\title{
Pre|N/18/Ew id
}

- 2002015913

563660

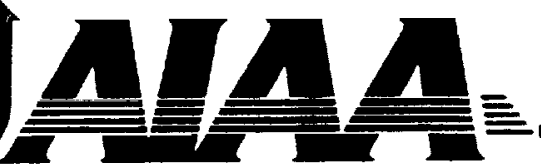

AIAA 2002-0910

Probabilistic Design Of A Mars Sample Return Earth Entry Vehicle Thermal Protection System

John A. Dec and Robert A. Mitcheltree NASA Langley Research Center Hampton VA.

$40^{\text {th }}$ Aerospace Sciences Meeting \& Exhibit 14-17 January 2002
Reno, Nevada

For permission to copy or to republish, contact the copyright owner named on the first page. For AIAA-held copyright, write to AIAA Permissions Department, 1801 Alexander Bell Drive, Suite 500, Reston, VA, 20191-4344. 


\title{
PROBABILISTIC DESIGN OF A MARS SAMPLE RETURN EARTH ENTRY VEHICLE THERMAL PROTECTION SYSTEM
}

\author{
John. A. Dec and Robert A. Mitcheltree \\ National Aeronautics and Space Administration \\ Langley Research Center \\ Hampton VA 23681-2199
}

\begin{abstract}
The driving requirement for design of a Mars Sample Return mission is to assure containment of the returned samples. Designing to, and demonstrating compliance with, such a requirement requires physics based tools that establish the relationship between engineer's sizing margins and probabilities of failure. The traditional method of determining margins on ablative thermal protection systems, while conservative, provides little insight into the actual probability of an over-

temperature during flight. The objective of this paper is to describe a new methodology for establishing margins on sizing the thermal protection system (TPS). Results of this Monte Carlo approach are compared with traditional methods.
\end{abstract}

\section{INTRODUCTION}

The culmination of a Mars Sample Return (MSR) mission ${ }^{1}$ requires an Earth Entry Vehicle (EEV) that must safely transport Mars samples through Earth's atmosphere to a recoverable location on the surface. While there exists no evidence that these samples pose any threat to terrestrial biology, the samples will be handled as if they contain hazardous material. The EEV and the sample container(s) must, therefore, assure containment of the samples during this transit. In particular, it is anticipated that NASA's Planetary Protection Officer will levy a requirement on the MSR Mission that the probability of inadvertent release of Mars material into Earth's biosphere be less than a specified small value.
The task of designing to, and demonstrating compliance with, such a requirement (in the absence of fleet-level heritage in entry systems) can be accomplished by coupling the vehicle's engineering design efforts with those of risk assessment early in the design process. Phenomenological analysis and tests used by engineers to size the design's components must be linked with logical risk models to incorporate quantitative risk data to guide design decisions. Unfortunately, designers and risk assessment experts seldom work within the same organizational structure, each possess their own oblique vocabulary, and often the risk assessment activities do not formally begin until completion of the detailed design. System trade studies conducted early in the development phase involve detailed quantification of performance parameters but little more than qualitative assessments of risk. Risk based design requires these two activities be concurrent and of balanced fidelity.

One example of a hard link between risk assessment and quantitative engineering analysis would be a physics based tool which establishes the relationship between engineer's safety margins and probabilities of failure. A collection of such tools covering the major risk elements of the design could then be integrated into the logical risk model for the vehicle and allow system level trades.

The simplest approach to returning Mars samples safely through Earth's atmosphere involves an entirely passive $\mathrm{EEV}^{3}$ shown in Figure 1. This approach circumvents the failure modes of a parachute descent system by replacing that system with sufficient energy absorbing materials to "cushion" the samples during the ensuing ground impact. This approach removes most of the

Copyright 2002 by the American Institute of Aeronautics and Astronautics, Inc. No copyright is asserted in the United States under Title 17 , U.S. Code. The U.S. Government has a royalty-free license to exercise all rights under the copyright claimed herein for Governmental purposes. All other rights are reserved by the copyright owner. 
failure modes associated with traditional entry capsules but still must demonstrate high reliability of its thermal protection system.

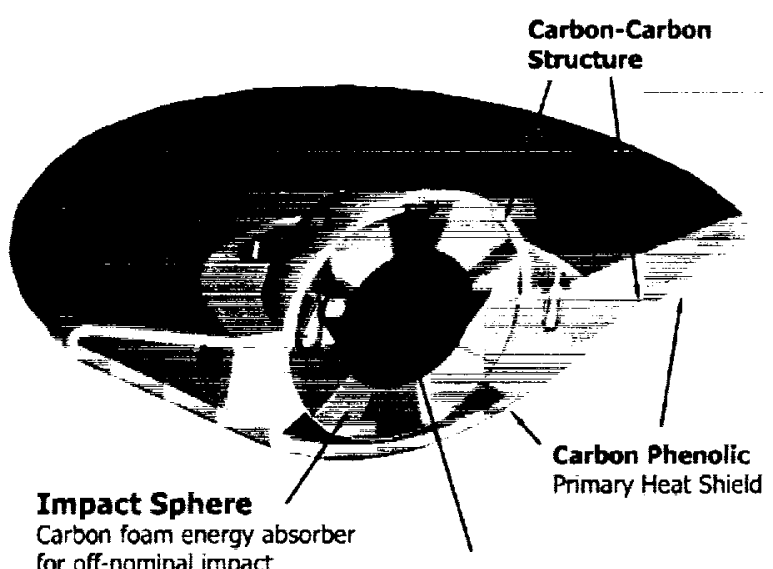

for off-nominal impact

Orbiting Sample (OS)

Mars soil sample

Figure 1. Schematic of entirely passive Earth Entry Vehicle.

The objective of this paper is to describe a new methodology for establishing thickness margins on the thermal protection system (TPS) for entry vehicles. This methodology provides more insight into the relationship between thickness margin and probability of maintaining bondline temperatures within specified requirements than the traditional method of establishing TPS sizing margins. The approach is a Monte-Carlo analysis that links a three degree-of-freedom trajectory calculation and a distributed heating environment prediction including turbulence effects with a material response calculation. Simply stated, the Monte-Carlo analysis combines physics based tools that predict the environment with those used to predict the TPS material's response to that environment.

Results from the present approach with twelve statistically varying parameters are compared with those of the traditional approach for the MSR EEV case. Incorporation of the present methodology within the entire vehicle or mission Probabilistic Risk Assessment (PRA) is straightforward. In addition, this new methodology has application to any atmospheric entry vehicle design that seeks to establish a more rigorous relationship between TPS margins and probability of success.

\section{A SIMPLIFIED FAULT TREE FOR FAILURE}

There exists numerous ways to decompose the potential causes of functional failure of a structural element of a vehicle. For the present work, it is convenient to represent a simplified form as follows. Failure of a vehicle's element, for example failure of the heatshield to limit temperatures in the underlying structures, could result if the environment it experiences during the mission (i.e. heating load) exceeds the expected values. Failure could also result from improper prediction of that element's response to its expected environment. Finally, failure could be the result of the element's physical properties were not as expected (i.e. manufacturing flaws or degradation in properties during previous mission phases). If any one of these errors, or a combination of errors from all three are sufficient to overcome the margin included in the design, the element fails to perform its function.

\section{THERMAL PROTECTION SYSTEM}

The function of an entry vehicle's thermal protection system (TPS) is to protect underlying materials from the intense convective and radiative heating associated with hypersonic entry into the Earth's atmosphere. TPS failure modes can be divided into two categories: 1) burn-through failure modes and 2) over-temperature failure modes. Bum-through failures are associated with catastrophic failure of the protective layer leading to direct exposure of the underlying structures to the flowfield. Over-temperature failures are associated with inadequate thermal insulation performance of the layer leading to TPS-structure bondline temperatures in excess of the specified limits. Determining the probability of a burn-through failure requires extensive testing in relevant environments of the material with all expected manufacturing variants. Additional thickness added to a TPS layer may do little to decrease the probability of a burn-through failure. Thickness margin is, however, effective in decreasing the probability of bondline over-temperature. The present method, which seeks to define the relationship between thickness margin and the probability of substructure overtemperature, addresses only the over-temperature failure mode.

There are numerous challenges associated with 1) understanding the heatshield's environment during entry, 2) understanding how the heatshield will respond to that environment, and 3) understanding the possible variations in the TPS material properties. If quantitative data were collected for each of these uncertainties, there remains the challenge of combining 
this information into a phenomenological model to determine the appropriate margins to apply when sizing the heatshield.

Margins for ablative TPS systems have traditionally been determined in one of two ways: First, a stacked worst case approach in which all parameters are set to their worst case value and the required thickness margin computed; and second, a lumped uncertainties RootSum-Square approach. For the latter, the uncertainties in the environment are typically lumped together and a required thickness margin is computed assuming no uncertainties in the materials response to that environment. Next, the required thickness margin to cover uncertainty in the material's properties to the nominal environment is computed. The root-sumsquare (RSS) of these two independent margins is then defined as the required thickness margin. Additional uncertainties in surface recession, manufacturing tolerance and another factor of safety may then be added on top of that RSS value to define the final TPS thickness.

While the traditional method described above has proved to be a successful design practice, the interdependent nonlinearity of the problem does not permit a true quantification of the actual risk for this approach. In addition, changing the grouping of uncertainties in the RSS equation produces different results. Finally, for those approaches that add an additional safety factor and a manufacturing tolerance at the end of the process, there is no justification for safety factor values selected and no information on the effect of probability of failure from either addition. Results will be presented illustrating the correlation between heatshield safety margin and the probability that underlying materials are exposed to temperatures that exceed a specified maximum temperature failure criterion.

\section{UNCERTAINTIES IN THE ENVIRONMENT}

Uncertainties in the thermal environment encountered by a vehicle's TPS during atmospheric entry are a combination of uncertainties associated with the flight trajectory of the vehicle and the prediction of the environment at each point in the trajectory.

For a ballistic entry, the initial state at the edge of the atmosphere (i.e. initial velocity and initial entry angle), the vehicle's ballistic coefficient, and the atmospheric properties determine the flight trajectory. Uncertainties in each of these parameters result in a dispersed set of possible trajectories. For a given time point in one of these trajectories, each spatial point on the vehicle will be subjected to a particular heating rate. The present Monte-Carlo analysis includes a three degree-offreedom trajectory simulation with three statistically varying parameters. Variations in the initial velocity, initial flight path angle, and the vehicle's ballistic coefficient are considered. Variations in atmospheric properties were not included.

The trajectory simulation includes a convective heating prediction from Chapman's equation ${ }^{4}$ and a radiative heating prediction from the Sutton-Graves correlation ${ }^{5}$. These predictions estimate the heating history at the vehicle's stagnation point. This heatpulse is shown in Figure 2 for the present nominal case. A high fidelity computational analysis is then computed at the peak heating conditions to establish a correction factor to the estimates mentioned above. The high fidelity solution also predicts the spatial distribution of heating at other points on the vehicle. The normalized laminar heating distribution at 11 points around the body is shown in Figure 3 . By assuming this normalized distribution applies at all times during the heatpulse, a laminar heatpulse for each of the 11 points is generated.

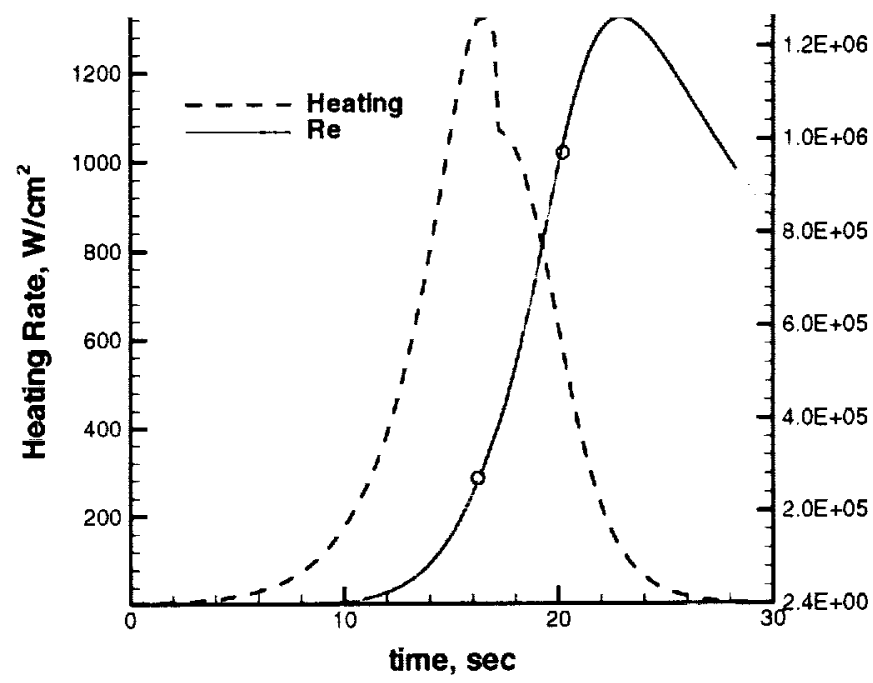

Figure 2. Nominal entry heating and Reynolds Number pulses.

Thermochemical nonequilibrium computational analysis tools capable of predicting the laminar convective heating about an entry capsule at one of these trajectory points have reached a certain level of maturity. Uncertainties, however, still exist in those predictions. One of the statistically varying parameters is an uncertainty in this laminar prediction. A similar uncertainty is applied to the radiative heating prediction. 


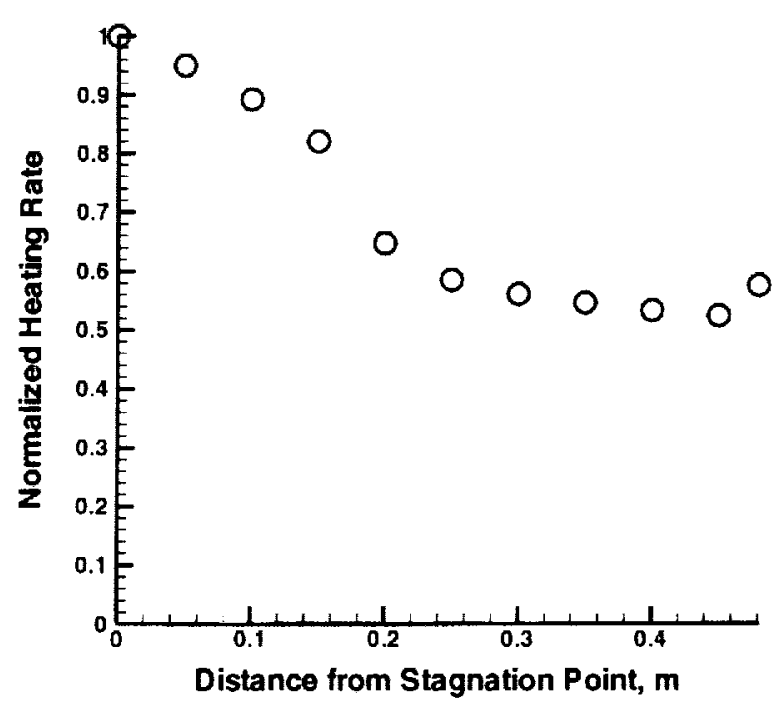

Figure 3. Normalized heating distribution on the forebody at peak heating conditions.

In addition, transition to turbulence and the augmentation of heating due to turbulence introduce uncertainties into predictions of the environment. For the EEV entry conditions, the primary mechanism of transition appears to be roughness. Roughness height Reynolds number is a similarity parameter that has been successful in predicting turbulence transition in this case for blunt vehicles. In the present analysis, computational solutions were generated at the peak heating point and the peak pressure point in the trajectory. Values for the roughness height Reynolds number can be extracted from these two solutions. However, this extraction requires a-priori knowledge of the surface roughness height. Surface roughness is intended to be an uncertainty in the present MonteCarlo analysis. Therefore, roughness height Reynolds numbers were extracted at five different roughness heights for the two solutions generated. Examination of the data revealed that the relationship between this Reynolds number and the surface roughness was quadratic in surface roughness. Curve fits were generated to define this quadratic relationship at each of the 11 points for both of the solutions as shown in Figure 4.

To handle the variation in roughness height Reynolds number with time, the two solutions available were utilized to establish a linear correlation with flight Reynolds number based on vehicle diameter. The flight Reynolds number for the nominal trajectory was input along with the heating values discussed earlier. Prediction for the roughness height Reynolds number at each of the 11 points on the forebody at each of the times during the trajectory is then accomplished by 1 )

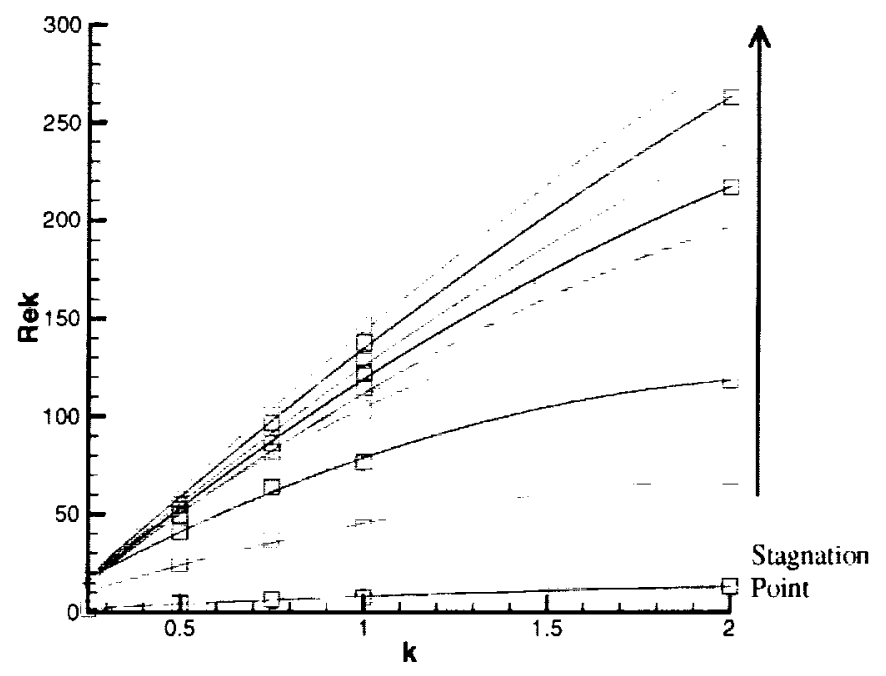

Figure 4. Variation in roughness height Reynolds number with roughness height for 11 points around the body at the maximum pressure trajectory point.

defining the Reynolds number at each point on the body for peak heating and peak pressure for the current surface roughness, then 2 ) applying the linear flight Reynolds number adjustment to scale those values to each time during the entry. Each of these is then compared with the critical roughness height Reynolds number transition criteria (currently 250 with 3 -sigma uncertainty of 60 ). If the value exceeds the criteria, local transition is assumed and the heating value is increased to account for augmentation to heating as a result of transition. Presently this augmentation factor is 2.5 with 3 -sigma uncertainty of 1.5 .

The result at this point in the simulation is a time varying heatpulse for each of the 11 points on the body that includes turbulence effects if the transition criteria is met. This heatpulse includes 3 statistically varying parameters associated with predicting the trajectory, two parameters associated with the laminar heating and three parameters associated with transition to turbulence. It remains to then examine the material's response to this environment at each point on the body to establish if the maximum bondline temperature failure criteria is exceeded.

\section{UNCERTAINTIES IN THE MATERIALS RESPONSE}

The present Monte-Carlo analysis contains the Charring Material Thermal Response and Ablation Program (CMA) ${ }^{6}$. CMA is a finite difference computational tool used to compute the 1-D transient thermal response of a 3-D material that can ablate from the surface and decompose in-depth. Although the in-depth energy 
balance is solved implicitly, it is linked explicitly to both the decomposition and the surface energy balance calculations. This explicit link is a minor limitation in the program. A prediction of the time history of the bondline temperature for the nominal heating case at the stagnation point is shown in Figure 5.

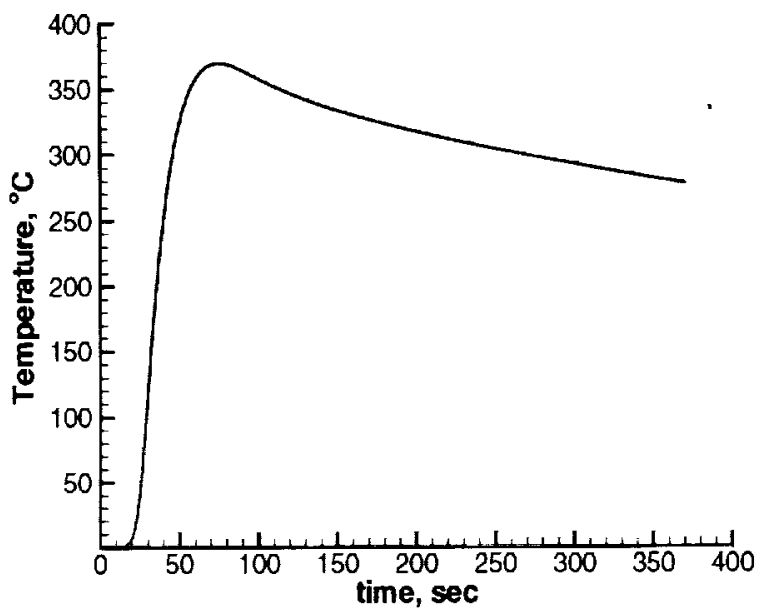

Figure 5. Bondline temperature from the material response calculation on $1.095 \mathrm{~cm}$ carbon-phenolic heatshield.

There are numerous uncertainties associated with this analysis. For the present Monte-Carlo analysis, uncertainties in the thermal conductivity and specific heat of both the virgin material and the char are included as statistically varying parameters. In addition, uncertainties in the virgin density are included for a total of five statistically varying parameters associated with the material response calculation. Due to the complex nature of the pyrolysis gas enthalpy and surface thermochemistry tables in CMA, variations in these parameters were not considered at this time.

Computation of the 1-D ablation and thermal conduction results in a bondline temperature history at each of the 11 points for the case being examined. These histories are then compared against the bondline temperature constraint. If the bondline temperature at any point on the body at any time during the entry exceeds the failure criteria (currently $370^{\circ} \mathrm{C}$ ), the case is counted as a failure.

\section{SUMMARY OF VARIABLES IN MONTE CARLO}

Table 1 summarizes the statistically varying inputs to the bondline overtemperature Monte-Carlo. The objective of this paper is to illustrate the present methodology, to that end, an attempt was made to select uncertainties that were reasonable, but these values are for illustration only.

Note that an uncertainty about TPS thickness is included to embed manufacturing tolerances into the analysis. This framework could also allow uncertainties in the failure criteria as defined by the maximum allowable bondline temperature. This uncertainty was not considered in the results presented.

\begin{tabular}{|c|c|c|}
\hline Parameter & $\begin{array}{l}\text { Mean } \\
\text { Value }\end{array}$ & $\begin{array}{c}3 \sigma \\
\text { Uncertainty }\end{array}$ \\
\hline $\begin{array}{l}\text { Initial Velocity } \\
(\mathrm{m} / \mathrm{s})\end{array}$ & 11553 & 0.0 \\
\hline $\begin{array}{c}\text { Ballistic Coeff } \\
\left(\mathrm{kg} / \mathrm{m}^{2}\right)\end{array}$ & 46.0 & 5.0 \\
\hline $\begin{array}{c}\text { Flight Path Angle, } \\
\text { (deg) }\end{array}$ & -24.8 & 0.9 \\
\hline $\begin{array}{l}\text { Radiative Heating } \\
\text { Factor }\end{array}$ & 1.0 & $18 \%$ \\
\hline $\begin{array}{c}\text { Convective Heating } \\
\text { Factor }\end{array}$ & 1.0 & $18 \%$ \\
\hline $\begin{array}{c}\text { Surface Roughness, } \\
(\mathrm{mm})\end{array}$ & 0.4 & $0.6^{*}$ \\
\hline $\begin{array}{c}\text { Critical Roughness Re } \\
\text { Criteria }\end{array}$ & 250 & 60 \\
\hline $\begin{array}{l}\text { Thermal Conductivity } \\
\text { Factor, Virgin }\end{array}$ & 1.0 & $15 \%$ \\
\hline $\begin{array}{l}\text { Thermal Conductivity } \\
\text { Factor, Char }\end{array}$ & 1.0 & $15 \%$ \\
\hline $\begin{array}{c}\text { Specific Heat Factor, } \\
\text { Virgin }\end{array}$ & 1.0 & $15 \%$ \\
\hline $\begin{array}{c}\text { Specific Heat Factor, } \\
\text { Char }\end{array}$ & 1.0 & $15 \%$ \\
\hline Density Factor & 1.0 & $15 \%$ \\
\hline TPS Thickness, $(\mathrm{cm})$ & 1.0945 & 0.12 \\
\hline
\end{tabular}

Table 1. Summary of input parameters and 3-sigma uncertainties.

Variations for the parameters are assumed to be normal distributions in the present example. This distribution may not be representative of data collected for a specific application. Distributions that best fit the available data should be employed ${ }^{7.8}$. For example, manufacturing tolerances may be best represented by a uniform distribution. 


\section{RESULTS}

The present Monte-Carlo simulation includes a three degree-of-freedom trajectory calculation, a prediction of the distributed heating including turbulence effects, a CMA material response calculation, and manufacturing tolerances. The combined computational cost of the calculations is approximately 31 seconds per sample on an $850 \mathrm{MHz}$ processor. Of those 31 seconds, 30 seconds are spent in the CMA calculation. Since CMA uses an explicit numerical algorithm to solve the decomposition and surface energy balance equations, the time step is recomputed for each CMA calculation to optimize run time and minimize numerical instabilities. Consequently, variations in the computational time for each sample exist.

A series of 2000-10000 sample Monte-Carlo simulations were performed to establish the relationship between the probability of exceeding the bondline temperature constraint and the thickness margin added. That relationship is shown in Figure 6. The figure reveals that $13.6 \%$ thickness margin is required to decrease the probability of bondline overtemperature to 3 in 1000 for the assumed set of uncertainties.

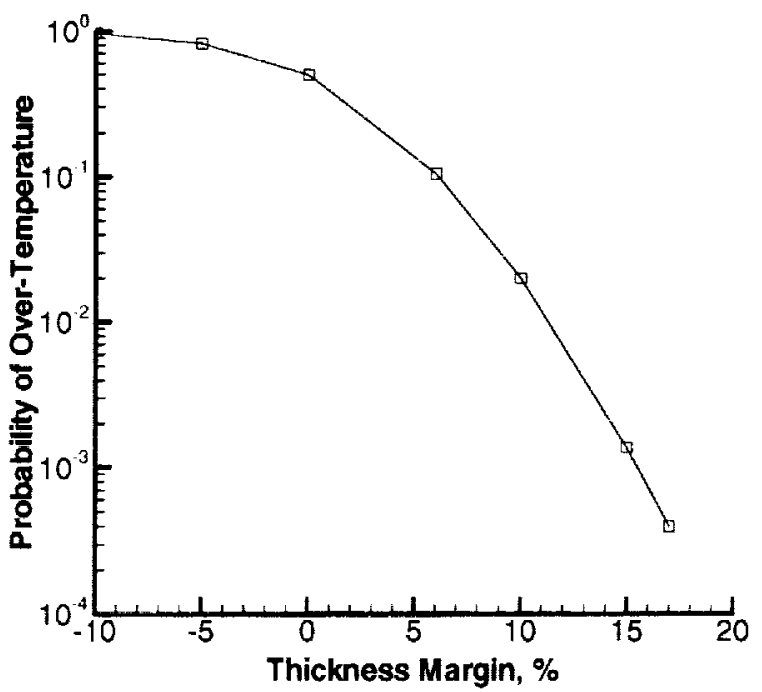

Figure 6. Relationship between probability of bondline over-temperature and thickness margin for the assumed uncertainties.

Examination of the over-temperature failures during these runs indicates that all failures occurred at the stagnation point. This indicates that turbulence transition on the vehicle flank is not occurring sufficiently early during the heatpulse to increase heating on the flank points. Variation in the nominal roughness height Reynolds number criteria revealed

\begin{tabular}{|c|c|c|}
\hline \multirow[t]{2}{*}{ Parameter } & \multicolumn{2}{|c|}{$\begin{array}{c}\text { Thickness Margin to cover } 3 \sigma \\
\text { Uncertainty }\end{array}$} \\
\hline & $\begin{array}{c}\text { Individual } \\
\text { Contributions } \\
\end{array}$ & $\begin{array}{c}\text { Lumped } \\
\text { Contributions } \\
\end{array}$ \\
\hline $\begin{array}{c}\text { Initial } \\
\text { Velocity }\end{array}$ & $0 \%$ & \\
\hline $\begin{array}{c}\text { Ballistic } \\
\text { Coeff }\end{array}$ & $0.32 \%$ & \\
\hline $\begin{array}{l}\text { Flight Path } \\
\text { Angle, }\end{array}$ & $1.87 \%$ & \\
\hline $\begin{array}{l}\text { Radiative } \\
\text { Heating }\end{array}$ & $0.23 \%$ & $2.58 \%$ \\
\hline $\begin{array}{l}\text { Convective } \\
\text { Heating }\end{array}$ & $1.87 \%$ & \\
\hline Surface Roughness & $0 \%$ & \\
\hline $\begin{array}{l}\text { Critical Roughness } \\
\text { Re Criteria }\end{array}$ & & \\
\hline $\begin{array}{c}\text { Thermal } \\
\text { Conductivity, } \\
\text { Virgin } \\
\end{array}$ & $3.70 \%$ & \\
\hline $\begin{array}{c}\text { Thermal } \\
\text { Conductivity, } \\
\text { Char }\end{array}$ & $4.71 \%$ & $18.59 \%$ \\
\hline $\begin{array}{l}\text { Specific Heat, } \\
\text { Virgin }\end{array}$ & $2.79 \%$ & \\
\hline $\begin{array}{l}\text { Specific Heat, } \\
\text { Char }\end{array}$ & $0.96 \%$ & \\
\hline Density Factor & $5.25 \%$ & \\
\hline RSS & $8.9 \%$ & $18.8 \%$ \\
\hline TPS Thickness & $11.0 \%$ & $11.0 \%$ \\
\hline RSS + TPS thick & $19.9 \%$ & $29.7 \%$ \\
\hline Stacked Wc & st Case & $33.8 \%$ \\
\hline
\end{tabular}

Table 2. Independent and lumped contributions to thickness margin.

that this critical value would have to be as low as 100 (rather than the suggested value of 250) for turbulence transition to be important for this set of assumed inputs.

The same analysis tools can be used to examine the relative impact of each of the statistically varying parameters. Table 2 presents each parameter and the required thickness margin necessary to cover the 3 sigma uncertainty in this parameter.

Table 2 reveals that in this example, the single dominant contributor is the uncertainty in TPS manufacturing tolerances. In addition, the contributions from the material response parameters are much larger than the contributions from the environmental 
parameters. These observations are dependent on the assumed uncertainties in these parameters and may not be representative for a given application.

Table 2 also contains two results from traditional means of establishing margins. The stacked worse case prediction is $33.8 \%$ and a lumped uncertainty RootSum-Square approach with manufacturing tolerances added predicts $29.7 \%$. Using Fig. 6, a comparison of these values with the $13.6 \%$ value for 3 -sigma uncertainty ( 3 in 1000 ) reveals that the traditional means of computing margins results in much lower probabilities of over-temperature, approximately $1 \times 10^{-8}$ and $5 \times 10^{-6}$ respectively.

\section{CONCLUSIONS}

The traditional methods of determining margins on ablative thermal protection systems, while conservative, provide little insight into the actual probability of an over-temperature during flight. Accurate quantification of this probability can be accomplished with the present method (if accurate input uncertainties are obtained). This quantification is accomplished by coupling physics-based analysis for the trajectory, the heating, and the material response into a single Monte-Carlo analysis. The present method includes turbulence transition and manufacturing tolerances.

For the uncertainties of 12 input parameters used in this study, the Monte-Carlo analysis indicates that $13.6 \%$ margin is required to decrease the probability of over-temperature to 3 in 1000 . The traditional stacked worse case approach indicates the need for $33.8 \%$ thickness margin. An RSS between stacked worse case for the environment and for the material response uncertainties with a manufacturing tolerance added indicates $29.7 \%$. These required thickness margins translate into probabilities of over-temperature well below the 3 -sigma (3 in 1000) range.

Risk based design requires accurate quantification of failure probabilities to provide insight towards trade studies and quantification of an over all risk model. The present Monte-Carlo method provides this accuracy.

\section{ACKNOWLEDGMENTS}

The authors would like to thank Joseph Fragola (SAIC) for many helpful discussions. Robert Dillman, Ruth Amundsen, Scott Hill, Lynn Craig, Dr. Y. K. Chen,. Bernie Laub and Ray Dirling also provided assistance in aspects of this work.

\section{REFERENCES}

${ }^{\prime}$ Price, H, Cramer, K, Doudrick, S., Lee, W., Matijevic, J., Weinstein, S., Lam-Trong, T., Marsal, O., Mitcheltree, R., "Mars Sample Return Spacecraft Systems Architecture,"' IEEE Paper No., 1999.

${ }^{2}$ Hermann, R. J., and Lineberger, W. C. ,"Mars Sample Return: Issues and Recommendations," Task Group on Issues in Sample Return, Space Studies Board, National Research Council, ISBN 0-309-057337, National Academy of Sciences, 1997.

${ }^{3}$ Mitcheltree, R., Braun, R., Simonsen, L., Hughes, S., "Earth Entry Vehicle for Mars Sample Return," IAF paper No IAF-00-Q.3.04, October, 2000.

${ }^{4}$ Tauber, M. E., and Sutton, K.,"'Stagnation-Point Heating Relations for Earth and Mars Entries,' Joumal of Spacecraft and Rockets, Vol. 28, No. 1, 1991, pp 4042.

5Sutton, K., Graves, R. A., “'A General Stagnation Point Convective Heating Equation for Arbitrary Gas Mixtures," NASA TR-R-376, Nov., 1971.

6"User's Manual, Aerotherm Charring Material Thermal Response and Ablation Program", Acurex Corporation, Aerotherm Division, Mountain View, California, November, 1987.

${ }^{7}$ Fox, E. P., Safie, F., “'A Probabilistic Design Analysis Approach for Launch Systems," AIAA Paper 91-3372, June, 1991.

${ }^{8}$ Fox, E. P., Safie, F., "Statistical Characterization of Life Drivers for a Probabilistic Design Analysis," AIAA Paper 92-3414, July, 1992. 
